\title{
Prevalence of Geo-Helminths and Evaluation of Single Dose of Albendazole (400 mg) among School Children in Poumougne, Western Region, Cameroon
}

\section{Yamssi Cedric ${ }^{1}$, Kamga Simo Sabrina Lynda ${ }^{2}$, Noumedem Anangmo Christelle Nadia ${ }^{3}$ and Vincent Khan Payne ${ }^{2}$}

${ }^{1}$ Department of Biomedical Sciences, Faculty of Health Sciences, University of Bamenda, P.O. Box 39 Bambili, Cameroon. ${ }^{2}$ Department of Animal Biology, Faculty of Science, University of Dschang, P.O. Box 067, Dschang, Cameroon

${ }^{3}$ Department of Microbiology, Hematology and Immunology Faculty of Medicine and Pharmaceutical Sciences, University of Dschang, P.O. Box 96, Dschang, Cameroon

*Corresponding author: Yamssi Cedric, Department of Biomedical Sciences, Faculty of Health Sciences, University of Bamenda, PO Box 39 Bambili, Cameroon, Tel: (237)-677413547

\begin{abstract}
Background: Soil Transmitted Helminths (STHs) also called Geo-helminths are endemic in rural areas of developing countries. This study was conducted to determine the prevalence of Geo helminths, their risk factors and an evaluation of a single dose of Albendazole $400 \mathrm{mg}$ among infected School Children.

Methodology: Three High schools and Colleges, three Primary schools and a Nursery School were selected at random for sample collection. Stool was collected from each subject and analyzed using floatation technique and McMaster method respectively. Out of the three hundred and forty-one School children sampled, $21(6.16 \%)$ were found infected with Geohelminths so were treated with a single dose of Albendazole $400 \mathrm{mg}$. Twenty-one days after, their stool samples were again collected and examined.
\end{abstract}

Results: Ascaris lumbricoides, Ancylostoma duodenale, Cooperia and Trichuris trichiura species were encountered. Three cases of bi-parasitism Cooperia-Ankylostoma, Ascaris-Ankylostoma and Ascaris-Trichuris were noticed. Intensity was low for all the parasites encountered. There was a significant difference $(P<0.05)$ with respect to sex in favor of males. A significant reduction in prevalence rates and intensity were observed for post-treatment samples. A Cure Rate (C.R.) of $100 \%$ and an Egg Reduction Rate (ERR) of $100 \%$ for all STHs were also observed.

Conclusion: A single dose treatment with Albendazole 400 $\mathrm{mg}$ is effective for treatment of ascariasis, hookworm infection and trichuriasis. This study may contribute to the fight against intestinal helminthiasis among school age children in Bandjoun.

\section{Keywords}

STH, Prevalence, Infection, Intensity, Poumougne, Albendazole, School age children

\begin{abstract}
Abbreviations
ALB: Albendazole; CR: Cure Rate, EPG: Egg per gram of faeces; ERR: Egg Reduction Rate; NTDs: Neglected Tropical Disease; SPSS: Statistical Package for Social Science; STHs: Soil Transmitted Helminths; NECRHH: National Ethical Committee of Research for Human Health
\end{abstract}

\section{Introduction}

Intestinal Soil Helminthiasis is a parasitic disease belonging to the group of Neglected Tropical Diseases. According to WHO [1], nearly 1.5 billion people (24\%) of the world population suffer from the disease. Four parasites commonly responsible for this disease include: Ascaris lumbricoides, Ancylostoma duodenale, Necator americanus and Trichuris trichiura [2]. These are generally cosmopolitan parasites but are more frequently encountered in tropical regions [3,4]. In Sub-Sahara African counties, America, China and East Asia, more than 267 million preschool children and 568 million school-

Citation: Cedric Y, Lynda KSS, Nadia NAC, Payne VK (2020) Prevalence of Geo-Helminths and Evaluation of Single Dose of Albendazole (400 mg) among School Children in Poumougne, Western Region, Cameroon. Int J Trop Dis 3:036. doi.org/10.23937/2643-461X/1710036

Accepted: October 07, 2020; Published: October 09, 2020

Copyright: (C) 2020 Cedric $Y$, et al. This is an open-access article distributed under the terms of the Creative Commons Attribution License, which permits unrestricted use, distribution, and reproduction in any medium, provided the original author and source are credited. 


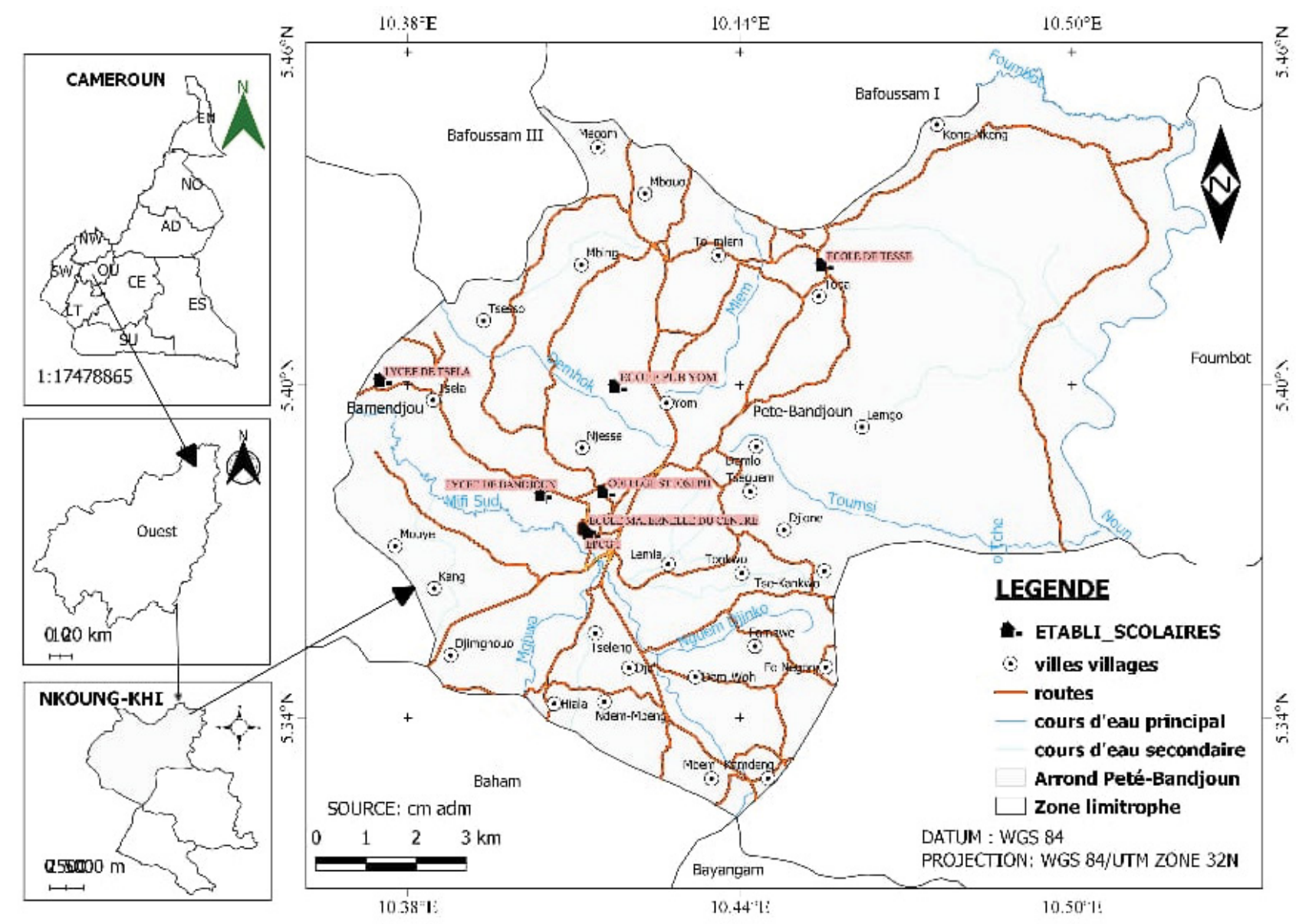

Figure 1: Nkoung-khi map [8].

age children live in regions where transmission of these parasites is intensive [1]. In Cameroon, the permanent secretariat of the National Schistosomiasis and Intestinal Helminthiasis Control Program (PNLSHI) in January 2006 reported that, two million people infected with schistosomes and more than 10 million people suffering from intestinal worms [5]. Common symptoms associated with parasitic Helminthiasis include: Malabsorption, anemia, diarrhea among others, while confirmation of parasites is based on parasitological examination of stool and duodenal fluid which aimed at finding the eggs and larvae of these parasites [6]. Control of Helminthiasis lies in chemoprevention, which consists of a periodic administration of single dose of anti-helminthic drugs such as: Praziquantel $40 \mathrm{mg} / \mathrm{kg}$ against schistosomes while Albendazole $400 \mathrm{mg}$ or Mebendazole 500 mg against soil-transmitted helminthiasis [7]. Prophylaxis is based on environmental sanitation, healthy lifestyle and personal hygiene. Report of previous study on gastrointestinal helminthiasis at Littoral Region, Cameroon revealed a prevalence rate of $25 \%$ [4]. The global objective, to which Cameroon subscribed, is to eliminate the morbidity due to helminthiasis in children from 2020. For this, at least $75 \%$ of children aged 12 to 59 months must be regularly treated [1]. Despite these efforts, many children are still affected today. Therefore, the aim of this study was to evaluate the efficacy of a Mebendazole $(500 \mathrm{mg}$ ) on Soil - transmitted helminth infections amongst school age children in Poumougne, Western Region, Cameroon. In order to contribute to the existing data on the efficacy of anthelminthics implemented in Cameroon, make recommendation for further regional and nationwide control programs.

\section{Methodology}

This study took place in Bandjoun (Figure 1) during the months of February to March 2019. Poumougne is located in the Department of Koung-Khi West Region-Cameroon (Figure 2). Bandjoun is limited to the North by Bafoussam I and Bafoussam III. In the South by the municipalities of Demdeng and Bayangam; to the East by the council of Foumbot and to the West by Bamendjou and Bafoussam III. This Sub-Division covers an area of approximately $115 \mathrm{~km}^{2}$ for a total population of approximately 47,405 inhabitants [8]. Figure 2 shows the map of schools choosen at random.

An ethical clearance was obtained from the National Ethical Committee of Research on Human Health (NECRHH) in Cameroon to visit each study location for sample collection. Before children were enrolled in the study, parents or guardians were given a comprehensive explanation of the risk and benefits of the study and consent forms were used to seek their willingness to allow their children participate. Questionnaires were used to collect demographic data for risk factors assessment. 


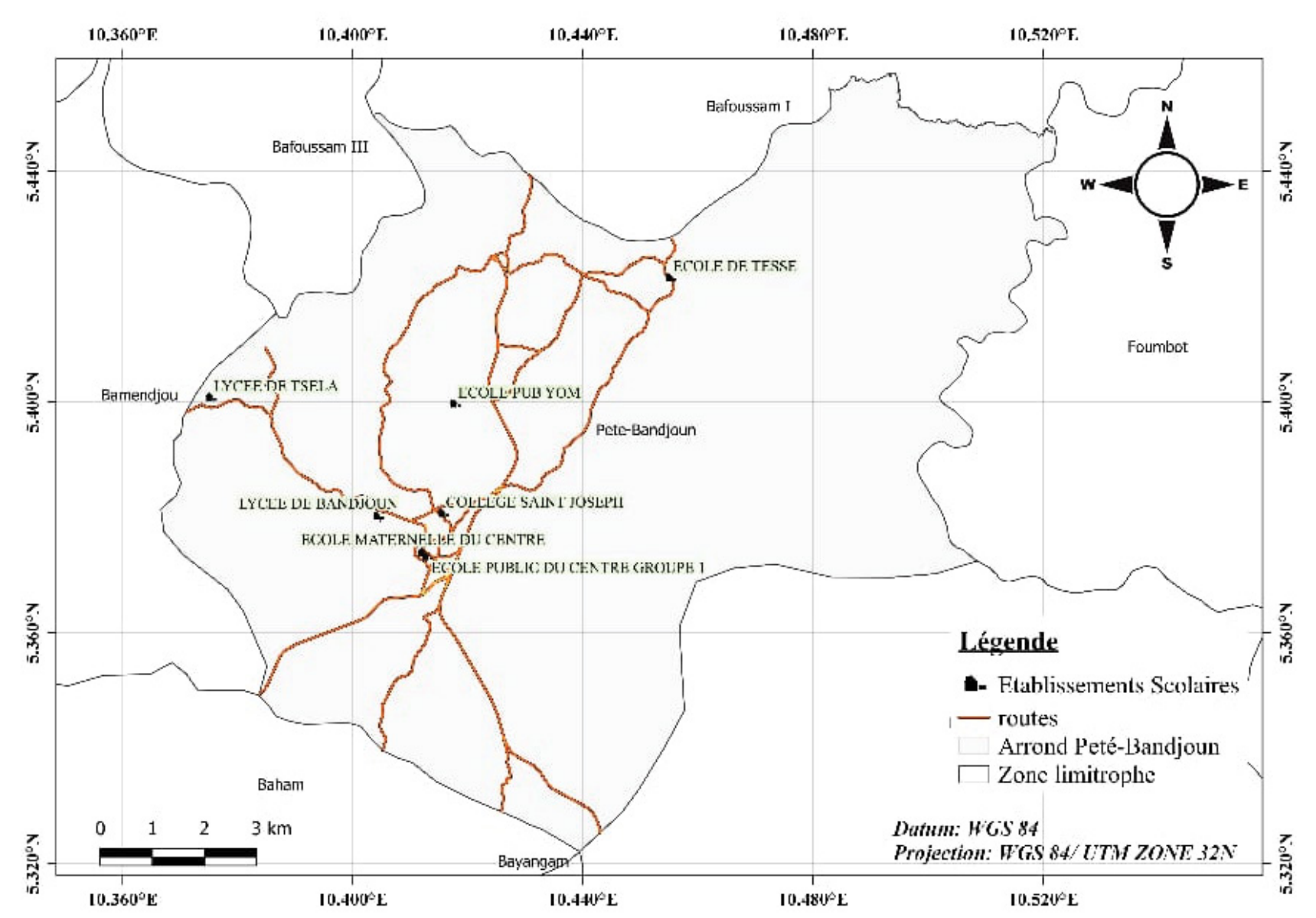

Figure 2: Map of schools choosen [8].

Table 1: Classification of nematodes according to intensity of infection [7].

\begin{tabular}{|l|l|l|l|}
\hline Geohelminths & Light (EPG) & Moderate (EPG) & Heavy (EPG) \\
\hline A. lumbricoides & $50-499$ & $500-999$ & $>1000$ \\
\hline T. trichiura & $50-499$ & $500-999$ & $>1000$ \\
\hline Hookworm & $50-1049$ & $1050-2000$ & $>2000$ \\
\hline
\end{tabular}

EPG: Egg per gram of feaces.

Seven schools were selected in Poumougne using a simple randomized method (Figure 2). These were: One Nursery School consisting of nursery I and nursery II pupils, three Primary Schools and two Secondary Schools. In each class samples were only taken from those children whose parents/guardians signed the consent forms. Samples were collected within the period of February and March, 2019 from school age children and analyzed for the presence of Soil Transmitted Helminthes (STH) Infections. Cure Rate (CR) and Egg Reduction Rate (ERR) were calculated to assess the efficacy of Mebendazole on geohelminths. The Mc Master Technic was used to determine intensity of worm infections and classification of egg count per gram (EPG) [7]. Parasitological analyses were carried out immediately after the first collection of stool samples using Floatation or Willis concentration Technics [7]. This was used to identify eggs or larvae of Helminths based on their morphology such as diameter or size, form, nature of the shell or membrane and colour to determine the presence of Helminths $[9,10]$. To each infected child, one tablet of Mebendazole ( $400 \mathrm{mg}$ ) was administered. After twenty-one days, stool samples, were recollected and examined to assess the efficacy of the treatment. All those who participated brought one specimen bottle as recommended by the investigator. Parents were instructed to notify on the questionnaire given to them the different adverse effects that occur within the week after treatment. The analyses of the specimens were carried out in the Research Unit of Biology and Applied Ecology (URBEA) of the University of Dschang. In each class samples were only taken from those children whose parents/guardians signed the consent. A. lumbricoides eggs were recognized based on their round, ova or elliptical shape with rough membrane. Trichuris trichiura were recognized based on their barrel-shaped eggs with clear Mucoid-appearing. The Mc Master technic described by the WHO [7] was used for quantitative analysis or determination of the number of Eggs Per Gram (EPG) of faeces. The intensity of infection was determined from the parasitic load according to 
the classification shown on Table 1.

Data collected were analyzed using Statistical Package for Social Science (SPSS) software version 20.0. Chi square $\left(\chi^{2}\right)$ test was used to assess differences in preva-

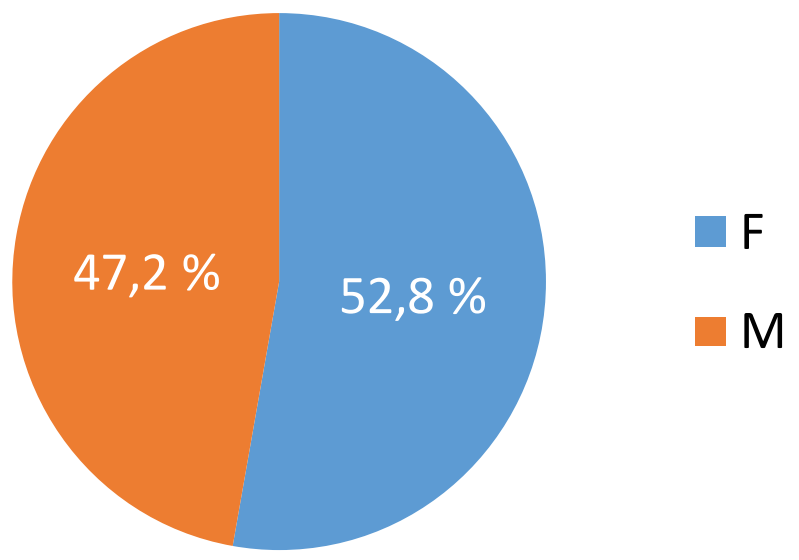

Figure 3: Population distribution according to sex. lence of STH infections. The Student t-test and one way analysis of variance (ANOVA) were used to compare mean egg Intensity. Statistical significance was set at $p$ $<0.05$.

\section{Results}

Figure 3 shows the population distribution of the subjects according to sex. Among the 341 participants 160 (47.2\%) were men and 181 (52.8\%) were women.

Table 2 shows the Prevalence of helminths according to sex. This table shows that, men were more (7.5\%) parasitized than women (6.7\%).

Table 3 shows the prevalence of helminths according to age group. Children aged between 10 and 14-yearsold were more parasitized than subjects belonging to other age groups.

Table 4 shows the prevalence of helminthes according to the level of formal education of the subjects. Primary School pupils were more parasitized followed by

Table 2: Prevalence of helminths according to sex.

\begin{tabular}{|l|l|l|l|l|}
\hline & \multicolumn{5}{|c|}{ Geo helminths } \\
\hline Sex & Ascaris I. & ankylostome & Cooperia & Tricocephal \\
\hline M & $5(3.1 \%)$ & $4(2.5 \%)$ & $3(1.9 \%)$ & $0(0 \%)$ \\
\hline F & $7(3.9 \%)$ & $4(2.2 \%)$ & $0(0 \%)$ & $1(0.6 \%)$ \\
\hline$\chi^{2}$ Critical Values & 0.154 & 0.026 & 3.384 & 0.897 \\
\hline DF & 1 & 1 & 1 & 1 \\
\hline P & 0.695 & 0.873 & 0.048 & 0.344 \\
\hline
\end{tabular}

P: P value; DF: Degree of Freedom; $\chi^{2}$ : Chi square

Table 3: Prevalence of helminths according to age group.

\begin{tabular}{|l|l|l|l|l|}
\hline & & Geo Helminths & & \\
\hline Age group (year) & A. lumbricoides & Ankylostoma & Cooperia & T. trichura \\
\hline$[0-4]$ & $0(0 \%)$ & $0(0 \%)$ & $0(0 \%)$ & $0(0 \%)$ \\
\hline$[5-9]$ & $5(2.9 \%)$ & $3(1.8 \%)$ & $0(0 \%)$ & $1(0.6 \%)$ \\
\hline$[10-14]$ & $6(4.8 \%)$ & $5(4 \%)$ & $3(2.4 \%)$ & $0(0 \%)$ \\
\hline$[15-19]$ & $0(0 \%)$ & $0(0 \%)$ & $0(0 \%)$ & $0(0 \%)$ \\
\hline$[20-23]$ & $1(2.9 \%)$ & $0(0 \%)$ & $0(0 \%)$ & $0(0 \%)$ \\
\hline$\chi^{2}$ Critical Values & 6.31 & 2.905 & 5.297 & 0.997 \\
\hline DF & 4 & 4 & 4 & 4 \\
\hline P & 0.177 & 0.574 & 0.258 & 0.91 \\
\hline
\end{tabular}

Table 4: Prevalence of helminths according to level of formal education.

\begin{tabular}{|l|l|l|l|l|}
\hline & \multicolumn{5}{|c|}{ Geo-helminths } \\
\hline Level of Formal Education & Ascaris & Ancylostoma & Cooperia & T. trichiura \\
\hline Primary Education & $9(3.9 \%)$ & $8(3.5 \%)$ & $3(1.3 \%)$ & $1(0.4 \%)$ \\
\hline Secondary & $3(3.2 \%)$ & $0.0(0 \%)$ & $0(0 \%)$ & $0(0 \%)$ \\
\hline Nursery & $0(0 \%)$ & $0(0 \%)$ & $0(0 \%)$ & $0(0 \%)$ \\
\hline$X^{2}$ Critical Values & 0.74 & 3.901 & 1.441 & 0.478 \\
\hline DF & 2 & 2 & 2 & 2 \\
\hline P & 0.691 & 0.142 & 0.486 & 0.788 \\
\hline
\end{tabular}




\section{0}

800

700

600

500

400

300
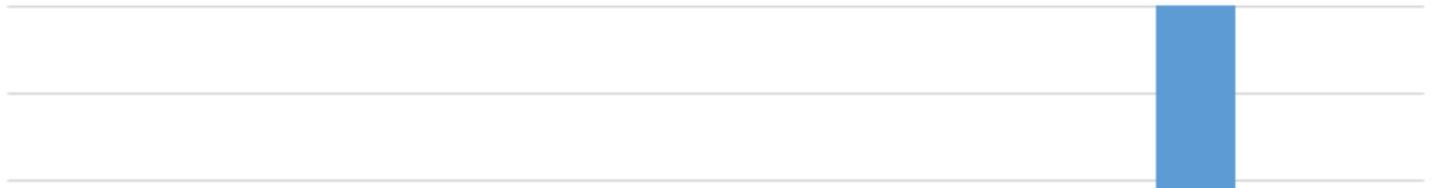

200

100

0

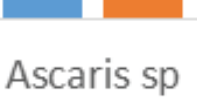

Ankylostoma sp

Cooperia sp

Trichuris trichura

\section{Geohelminths}

Figure 4: Intensity of helminthic infection according to sex.

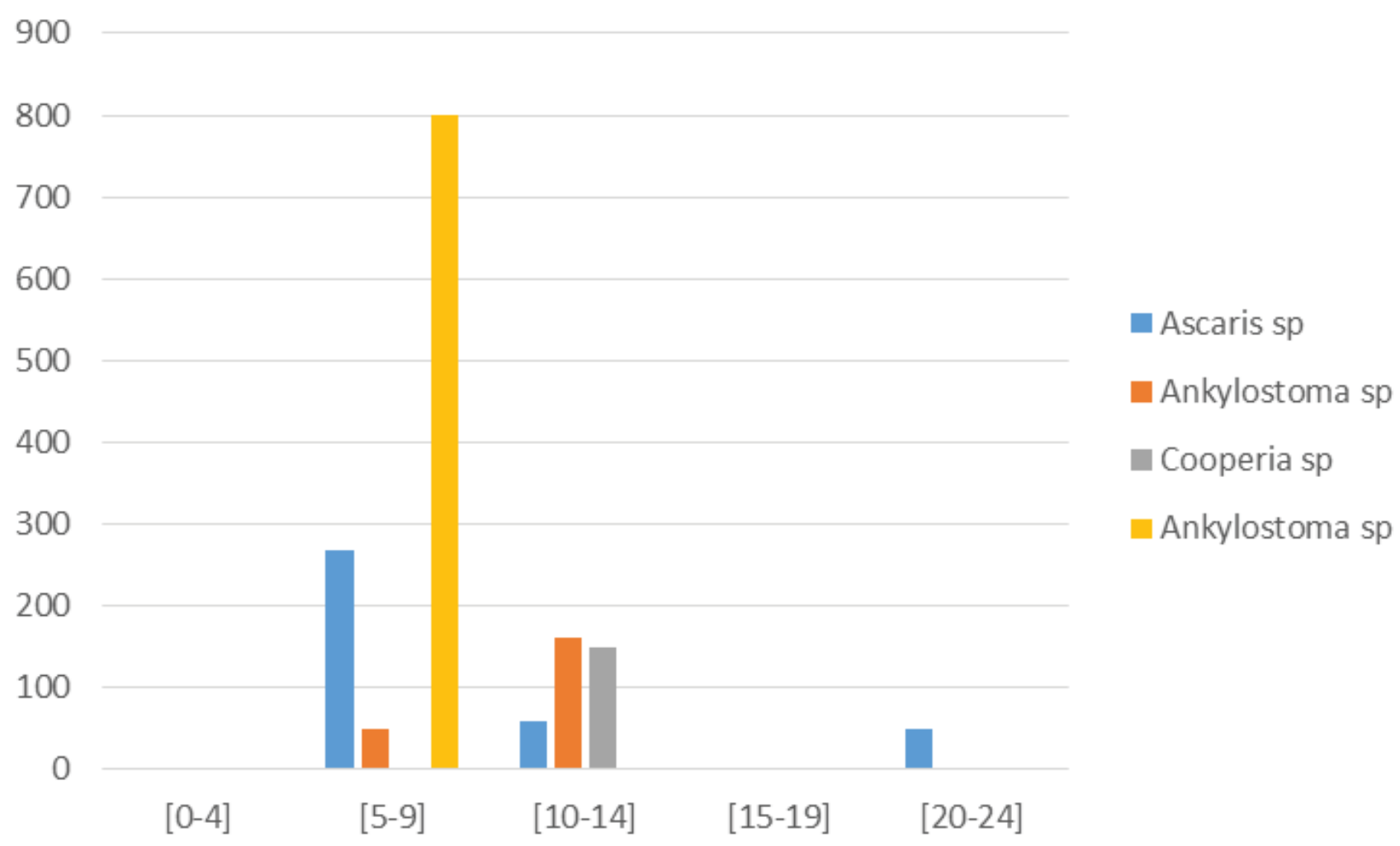

Figure 5: Intensity of helminthic infection according to age group.

secondary school children.

The intensity of helminthic infection according to sex is shown in Figure 4. The intensity of Ascaris, Ancylostome, does not vary in terms of sex. Only men were infected with Cooperia and women with Trichuris trichiura.

Figure 5 shows the intensity of helminthic infection according to age group. The intensity of Ascaris and Ankylostome did not with age. Cooperia was present only in children aged between 10-14 years-old and Trichuris trichiura in children aged between 5-9 years.

The intensity of helminthic infection with respect to level of formal education is revealed in Figure 6. The intensity of infection of Ascaris varies in terms of school 


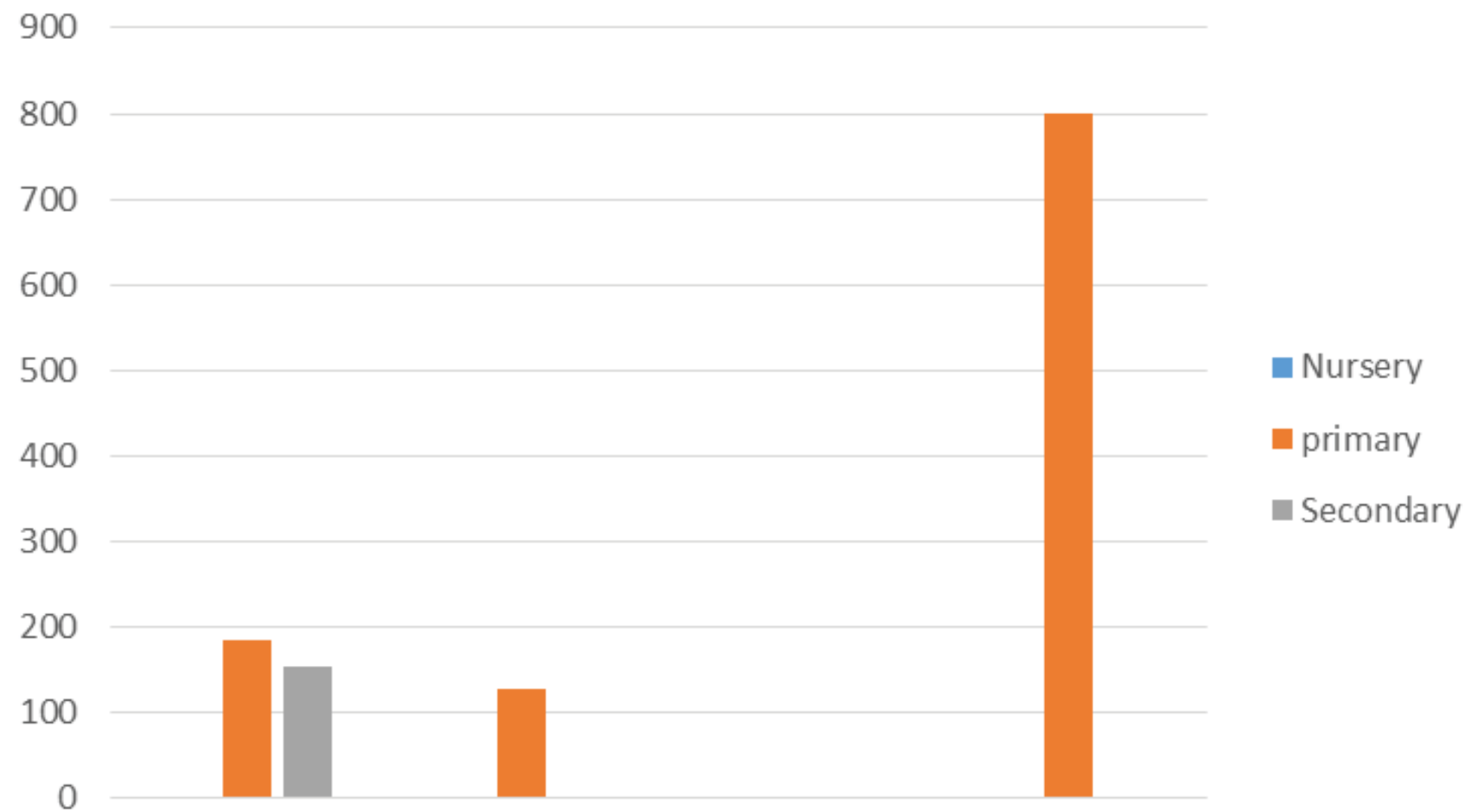

\section{Ascaris sp Ankylostoma sp Cooperia sp Trichuris trichura}

Figure 6: Intensity of helminthic infection with respect to level of formal education.

Table 5: Risk factors for helminthic infection.

\begin{tabular}{|c|c|c|c|c|c|c|}
\hline & & & Geohelminths & & & \\
\hline & & Ascaris sp & Ancylostoma & Cooperia & T. trichiura & $P$ value \\
\hline \multicolumn{7}{|l|}{ Risk Factors } \\
\hline \multirow[t]{3}{*}{ Religions } & Catholic & 7 & 7 & 1 & 1 & \\
\hline & Muslim & 2 & 0 & 0 & 0 & \\
\hline & Protestant & 3 & 1 & 1 & 1 & 0.304 \\
\hline \multirow[t]{2}{*}{ Cimented toilet } & Yes & 12 & 8 & 1 & 1 & \\
\hline & No & 0 & 0 & 2 & 0 & $<0.05$ \\
\hline \multirow[t]{2}{*}{ Availibility of water } & Yes & 12 & 8 & 1 & 1 & \\
\hline & No & 1 & 1 & 2 & 0 & \\
\hline \multirow[t]{2}{*}{ Presence of animals } & Yes & 1 & 1 & 1 & 1 & \\
\hline & No & 11 & 7 & 2 & 0 & $<0.05$ \\
\hline \multirow[t]{5}{*}{ Occupation of parent } & Farmer & 4 & 2 & 1 & 0 & \\
\hline & Trader & 1 & 0 & 1 & 0 & \\
\hline & Resourceful & 5 & 6 & 0 & 1 & \\
\hline & Civil servant & 1 & 0 & 0 & 0 & \\
\hline & Technician & 1 & 8 & 1 & 1 & $>0.005$ \\
\hline \multirow[t]{2}{*}{ Barefoot walking } & Yes & 0 & 7 & 0 & 0 & \\
\hline & No & 0 & 0 & 0 & 0 & \\
\hline
\end{tabular}

level. The primary school pupils had an intensity of infection between 0-200 EPG. Trichuris trichiura had the highest intensity of infection 800 EPG among primary school pupils. While a zero intensity rate was recorded for the Nursery and secondary schools except for Ascaris lumbricoides for secondary schools.

Analysis of Risk factors to helminthic infection revealed no statistical association between religion and helminthic infection ( $P$ value $>0.05$ ). On the contrary, there was a significant level of association between lack of Cimented toilets and helminthic infections ( $P$ value $<0.05)$. Similarly, the availability of water, presence of Animals, Occupation and walking barefoot were significantly associated with helminthic infections ( $P$ values $<$ 0.05) each (Table 5). 


\section{Discussion}

The general objective of this study was to assess the effectiveness of a single dose Albendazole $400 \mathrm{mg}$ in school age children and the risk factors in Bandjoun, Poumougne Sub-Division. Following the 341 stool samples analyzed, 21 were positive for intestinal helminths, with an overall prevalence rate of $6.15 \%$. This value is higher than reports of previous studies in Moungo, Littoral Region Cameroun with a prevalence rate of $4.2 \%$ and a prevalence rate of $4.3 \%$ in Algeria $[11,12]$. This prevalence rate is low compared to a previous report in Douala and Njombé, Littoral Region of Cameroon recorded with a prevalence rate of $26.59 \%$ and $23.4 \%$ in Fondenera Group (Menoua Division,) West Region of Cameroon $[6,13]$. This difference could probably be explained to a certain extent by the variations in socio-economic status, the regularly deworming campaigns aimed at lowering the prevalence of parasitic diseases in the various regions of Cameroon through the distribution of anthelminthic drugs and improvement of hygienic conditions.

Four (4) helminths were identified during the study, in particular: Ascaris sp with a prevalence of $3.5 \%, A n-$ kylostoma sp: $2.3 \%$; Trichuri trichiura $0.3 \%$ and Cooperia sp (0.9\%). These prevalence rates are low compared to a previous report in Dschang with $18 \%$ for A. lumbricoides, $36 \%$ for $T$. trichiura and $11 \%$ for hookworms [14]. The low infection rate in this study could be due to improvement of hygienic and sanitation conditions by the population and the public authorities. On the other hand, the results of this study are higher than the reports of Lehman, et al. [6] in Douala, Littoral Region of Cameroon, with a prevalence rate of $1 \%$ for Ascaris, $0.3 \%$ for hookworms and $0.3 \%$ for Trichuris trichiura [6]. Nevertheless, there is a similarity between these results and those of Payne, et al. [15] in Babadjou, with a prevalence rate of $4.2 \%$ for Ascaris and $1.9 \%$ for Trichuris trichiura.

Ascaris and hookworms were the most prevalent parasites with prevalence of $3.5 \%$ and $2.3 \%$ respectively these results are similar to those of Nkengazon, et al. [16] whose most prevalent parasites were Ascaris and Hookworm. Trichuris trichiura is the parasite that had the highest intensity of infection and was found only in primary school pupils. This may be because it is one of the helminths showing the highest level of resistance against Mebendazole or Albendazole drugs which are the most currently used drugs in developing countries.

The specific intensity of infection expressed in terms of mean concentration of eggs per gram (EPG $\pm S D$ ) of faeces of identified parasite varies from one species to another. The intensity of roundworm infection varies with sex while hookworm varies according to age. Children aged 5 to 9 years had a higher intensity of infection. This could be explained by the fact that female Ascaris generally lay a very large number of eggs (200,000 eggs/day) for about 300 days than other species [9,17]. According to Naish, et al. [18], Ascaris eggs survive for a longer period of 10 years in warm, humid environmental conditions which could be the cause of their long life span and constant infection. However, hookworm infection is believed to be due to the fact that the soil contains infective forms of these parasites which are transmitted to humans when they come into direct contact with the soil (agricultural work and walking barefooted). In this study, the prevalence rates of these helminths varied with sex. Males were more parasitized than females. The same observations were made by Reccurt, et al. [19] in a study conducted in Djohong, Adamaoua Region of Cameroon and Faye, et al. [20]. Most scholars have attributed this skewness to socio-cultural and behavioural differences between males and females children. Males obtained higher prevalence of intestinal parasitic infection because they get more freedom than females whose leisure hours are strictly controlled and restricted hence are less exposed to parasitic infections [21]. These results are contrary to a previous report in the city of Oran with varying prevalence rates according to sex [22].

The prevalence rates also varies according to school level, children of primary level were the most parasitized. This could be explained by the fact that children of primary school play and move everywhere, sometimes eat without getting their hands washed. In addition, primary school pupils urinate everywhere in different corners of the schools and come to play in the same places.

The overall intensity of infection was low and the average number of eggs per gram of stool was 285 EPG. This low intensity could probably be attributed the Government's mass drug distribution program to children and improved environmental sanitation in the studied locations. These results are similar to a previous report in Bafoussam, Western Region of Cameroon with low EPGs (EPG < 5000) [23]. Similarly, these results are similar with previous reports in the Southwest Region of Cameroon [17,23].

Administration of a single dose of Mebendazole (400 $\mathrm{mg}$ ), revealed $100 \%$ cure rate and $100 \%$ reduction in egg count. These results are similar to a previous report with a cure rate of $100 \%$ for round worms in Djohong in the Northern Region of Cameroon; and in Bafoussam, West Region of Cameroon [19,24,25]. This similarity may be because mebendazole was evaluated on the same helminths encounter in this study. On the other hand, the results contradicts a previous report of a cure rate of $80 \%$ and Eggs Reduction Rate (EER) of $52.3 \%$ and in a separate study carried out in seven countries of the world with $98.2 \%$ for Ascaris sp, $87.8 \%$ for hookworms and $46.6 \%$ for Trichuris sp and a reduction rate in the number of eggs of 99.5\% for Ascaris sp, 94.8\% for hookworms and $50.8 \%$ for Trichuris sp $[16,26]$. This over-all cure rate is due to the low infection of this study pop- 
ulation.

\section{Conclusion}

This study revealed low prevalence rates for intestinal helminthes. Four (4) helminths were identified during the study, in particular: Ascaris sp with a prevalence of 3.5\%, Ankylostoma sp: $2.3 \%$; Trichuri trichiura $0.3 \%$ and Cooperia sp (0.9\%). These low prevalence rates confirm the effectiveness of the regular de-worming campaigns put in place by the National Programm for Schistosomiasis and Intestinal Helminthiases against geohelminths by the government. Furthermore, this study confirms the therapeutic efficacy of a single dose of $400 \mathrm{mg}$ Albendazole against $A$. lumbricoides and hookworms.

\section{Availability of Data and Materials}

Data and material are available to other researchers upon request.

\section{Competing Interest}

The authors declared that they have no competing interest.

\section{Funding}

No funding.

\section{Acknowledgements}

All the children and their parents. We thank Mr. Michel Lontchi for the statistical analyses.

\section{Author's Contribution}

YC, KSSL, NACN and VKP contributed to the design of the study, data collection, led the analysis and drafting of the manuscript. All authors read and approved the final manuscript.

\section{Ethic Approval and Consent to Participate}

To carry out this research, an ethical clearance was obtained from the National Ethical Committee of Research for Human Health in order to ensure consent and confidentiality of the participants.

\section{Consent for Publication}

Not applicable.

\section{References}

1. OMS (2017) L'OMS recommande la vermifugation à grande échelle pour améléorer la santé et la nutrition des enfants.

2. MC Chukwuma, IM Ekejindu, NR Agbakoba, DA Ezeagwuma, IC Anaghalu, et al. (2009) The prevalence and risk factors of geohelminth infections among primary school children in Ebenebe town, Anambra state, Nigeria. Middle-East Journal of Scientific Research 4: 211-215.

3. P Saotoing, R Djonyang, DD Dereng, AM Njan N (2016) Enquête épidémiologique sur les parasitoses urinaires et intestinales chez les élèves des écoles primaires de l'arrondissement de Maga, Extrême-Nord Cameroun. International Journal of Biology and Chemical Sciences 10: 344-354.
4. GR Ngangnang, KP Vincent (2017) Prevalence and intensity of gastro-intestinal helminthiasis among school age children in Nkondjock, Littoral-Cameroon. International Journal of Biomedical Engineering and Clinical Science 3: 85-89.

5. PJ Wabo (2007) Effet des extraits de Canhium mannii (rubiacées) sur deux nématodes parasites strongylides: Ancylostoma caninum et Heligmosomaides polygynus. Thèse de Doctorat/ $\mathrm{PhD}$ en Biologie Animale, Université de Yaoundé I, 2.

6. LG Lehman, NL Kouodjip, BCF Bilong (2012) Diagnostic des parasitoses intestinales à l'aide de la microscopie à fluorescence. Médecine d'Afrique Noire 59: 378-381.

7. OMS (2015) Evaluation de l'efficacité des antihelmintiques contre la schistosomiase et les géohelminthiases.

8. (2011) Planification local sur financement PNDP, Commune de Pète-Bandjoun.

9. EJL Soulsby (1982) Helminths, arthropods and protozoa of domesticated animals. ( $7^{\text {th }}$ edn), Baillere Tindal, London, 805-809.

10. M Cheesbrough (1987) Medical Laboratory Manual for Tropical Countries. (2 ${ }^{\text {nd }}$ edn), Volume 1, Cambridge University Press, UK, 605.

11. MM Sabi (2015) The prevalence of gastrointestinal nematodes amongst residents in Melong, Littoral Region of Cameroon. Thesis submitted in partial fulfillment for the award of a Master degree in the University of Dschang, 74.

12. A Benouis, Z Bekkouche, Z Benmansour (2013) Etude épidémiologique des parasitoses intestinales humaines au niveau du C.H.U. d'Oran (Algérie). International Journal of Innovation 2: 613-620.

13. MC Ndounkang (2018) Facteurs de risque associé aux parasitoses gastro-intestinales chez les enfants scolarisés du Groupement Fondonera (Département de la Ménoua, Ouest Cameroun). Mémoire présenté en vue de l'obtention d'un Master of science en Biologie Animale à I'Université de Dschang, 60.

14. PJ Wabo, M Mpoame, EAP Nkeng, BCF Bilong (2012) Prevalence and intensity of infections of three neglected tropical diseases in patients consulted at a traditional health care center in Dschang West Cameroon. Trop Parasitol 2: 24-28.

15. VK Payne, FR Lontuo, GR Ngangnang, L Megwi, E Mbong, et al. (2017) Prevalence and intensity of infection of gastro-intestinal parasites in Babadjou West Region of Cameroon. International Journal of Clinical and Experimental Medical Sciences 3: 14-22.

16. L Nkengazong, SFB Natchema, LJ Ojong, AN Amvongo, NGI Kame, et al. (2018) Transmission pattern of neglected tropical diseases (STHs and amibiasis) in a rural community of South Cameroon: A need to involve all age groups in control strategy. Int J Curr Res Aca Rev 6: 83-91.

17. DWT Crompton, L Savioli (1993) Parasitoses intestinales et urbanisation. Bull World Health Organ 71: 143-149.

18. S Naish, JMc Carthy, GM Williams (2004) Prevalence, intensity and risk factors for soil transmitted helminthes infection in South Indian fishing village. Acta Trop 91: 177-187.

19. CP Raccurt, MT Lambert, O Mandji, J Bouloumie, C Ripert (1987) Etude épidémiologique des helminthiases intestinales à Djohong (Adamaoua- Cameroun). Ent méd et Parasitol 3-9.

20. O Faye, O N'dir, T Dieng, IB Bah, S Diallo, et al. (1998) Les parasitoses intestinales dans le bassin du fleuve Sénégal: 
Résultats d'enquêtes effectuées en milieu rural. Med Afrique Noire 4: 491-495.

21. Y Afriad (2018) Epidémiologie des parasitoses intestinales chez la population de la ville d'Agadir. Thèse présentée pour l'obtention d'un diplôme de Docteur en Epidémiologie, Université Cadi Ayyao, 25.

22. A Benouis (2012) Etude épidémiologique des parasitoses intestinales humaines dans la Région d'Oran: Apport de techniques complémentaires à l'examen coprologique direct pour confirmation du diagnostic, Mémoire de Master en Parasitologie Univ, Oran.

23. SBT Egbe, ME Esum, AE Achidi, L Jesper, CS Nambile (2018) Soil-transmitted Helminth infection in the Tiko Health District, South West Region of Cameroon: A post-intervention survey on prevalence and intensity of infection among primary school children. Pan Afr Med J 30: 74.
24. L Megwi (2013) Evaluation of the efficacy of albendazole, mebendazole and ivermectine on Geohelminths amongst school age children in Bafoussam. Thesis submitted in partial fulfillment for the award of a Master's degree in University of Dschang, 86.

25. L Nkengazon, F Njikoul, S Wanji, F Teukeng, P Enyong, et al. (2010) Prevalence of soil transmitted helminths and impact of Albendazole on parasitic indices in Kotto Barombi and Marumba II village (South-West Cameroon). African Journal of Environmental Science and Technology 4: 115121.

26. J Vercruysse, JM Behnke, M Albonico, SM Ame, C Angebault, et al. (2011) Assessment of the anthelmintic efficacy of albendazole in school children in seven countries where soil-transmitted helminths are endemic. PLos Negl Trop Dis 5: e948. 